\title{
Animal Models for Studying Pathophysiology of Hemodialysis Access
}

\author{
J.I. Rotmans ${ }^{*}, 1,2$ \\ ${ }^{I}$ Department of Nephrology, Leiden University Medical Center, The Netherlands \\ ${ }^{2}$ Einthoven Laboratory for Experimental Vascular Medicine, Leiden University Medical Center, The Netherlands
}

\begin{abstract}
Despite extensive efforts, most approaches to reduce arteriovenous (AV) access-related complications did not results in substantial improvement of AV access patency thus far. Part of this disappointing progress relates to incomplete understanding of the underlying pathophysiology of hemodialysis access failure. In order to unravel the pathophysiology of hemodialysis access failure, animal models that closely mimic human pathology are of utmost importance. Indeed, it is impossible to study the extremely complex response of the AV access at a molecular and cellular level in great detail in dialysis patients. Over the past decades, numerous animal models have been developed in an attempt to unravel the vascular pathology of AV access failure and to design new therapeutic strategies aimed to improve durability of these vascular conduits. While large animals such as pigs are suitable for intervention studies, murine models have the greatest potential to gain more insight in the molecular mechanisms underlying AV access failure due to the availability of transgenic mice. In the present review, we describe several existing models of AV access failure and discuss the advantages and limitations of these models.
\end{abstract}

Keywords: Animal models, hemodialysis access failure, intimal hyperplasia, pathophysiology, vascular remodeling.

\section{INTRODUCTION}

Vascular access related complications constitute a major cause of morbidity for patients on chronic hemodialysis. Despite extensive efforts to solve this clinically important issue, approaches to reduce arteriovenous (AV) accessrelated complications did not result in substantial improvement of AV access patency thus far. Part of this disappointing progress in the improvement of $\mathrm{AV}$ access patency relates to incomplete understanding of the underlying pathophysiology of hemodialysis access failure. Currently, there is consensus about variouspathological stimuli including local hemodyamic factors, repetitive punctioning, pre-existing vascular abnormalities, endothelial dysfunction, inflammation and platelet activation, that all contribute to intimal hyperplasia (IH), thrombosis and insufficient outward remodeling in arteriovenous fistulas (AVF) and grafts (AVG) [1-3]. However, there is ongoing debate about the relative contribution of all these stimuli in $\mathrm{AV}$ access failure.

In order to unravel the pathophysiology of hemodialysis access failure, animal models that closely mimic human pathology are of utmost importance. Indeed, it is impossible to study the extremely complex response of the AV access at a molecular and cellular level in great detail in dialysis patients. An adequate animal model is inexpensive, readily available and develops the pathology of interest in a relatively short period of time. When determining an appropriate animal model, not only the animal species but

*Address correspondence to this author at the Department of Nephrology, Leiden University Medical Center, P.O. Box 9600, 2300 RC Leiden, The Netherlands; Tel: + 3171 5262148; Fax: + 3171 5266868;

E-mail: j.i.rotmans@lumc.nl also the anastomotic site, the required anti-coagulatory therapy and the duration of follow up after surgery should be taken into account. Although cost, availability, ease of handling, postoperative mortality rate and vascular size are often used to guide animal selection, of primary importance is the need to select an animal model that correctly simulates the relevant aspect of human (patho)physiology [4].

Over the past decades, numerous animal models have been developed in an attempt to unravel the vascular pathology of $\mathrm{AV}$ access failure and to design new therapeutic strategies aimed to improve durability of these vascular conduits. While large animals such as pigs are suitable for intervention studies, murine models have the greatest potential to gain more insight in the molecular mechanisms underlying AV access failure due to the availability of transgenic mice. In the present review, we describe several existing models of AV access failure and discuss the advantages and limitations of these models.

\section{MURINE MODELS}

Because of their small size, murine models are limited to AVF since implantation of prosthetic grafts is not feasible. The first murine model of AVF failure was described in 2004 by Kwei and coworkers [5]. In their study AVFs were constructed using the carotid artery and the jugular vein of $\mathrm{C} 57 \mathrm{BL} / 6$ mice in an end-to-end manner using an intravascular catheter. Vessels were harvested at 1 day, 3 days, and 7 days after surgery. At time of harvest, $65 \%$ of AVFs were patent. AVF failure was mainly due to (acute) thrombosis. In the patent AVFs, an acellular band surrounding the vessel lumen was observed at day 1 after surgery, consistent with focal adherent thrombi. Furthermore, histological analysis at this early time point 
revealed substantial proliferation of vascular smooth muscle cells (VSMCs) and infiltration of inflammatory cells in the venous segment of the AVF. Finally, an increased diameter of the venous lumen was observed, especially in the anastomotic area. This model could be useful to study early venous adaptation in AVFs although the end-to-end configuration and the presence of an intravascular catheter limit the validity of this model for human AVFs. Yang et al., [6] described a similar murine AVF model in which the AVF was created with an end-to-end configuration using a cuff in $\mathrm{FVB} / \mathrm{NJ}$ mice. Follow up in their experiments was 28 days. Histological analysis of the venous outflow tract revealed mild $\mathrm{IH}$ that coincided with upregulation of matrix metalloproteinases. No data on vessel size/outward remodeling after surgery were reported.

An improved AVF model was introduced by Castier et al., [7] in which the end of the carotid artery is connected to the side of the jugular vein of C57BL/6 mice. AVFs were harvested up to 3 weeks after surgery. The authors elegantly showed that the neointimal lesions observed in the carotid artery consisted of abundant vascular smooth muscle cells (VSMCs) and a small number of macrophages. In addition, using LacZ transgenic mice showed that bone marrow stem cells did not contribute to VSMC accumulation in the intima of the carotid artery. Most likely due to technical reasons (e.g. cross-sectional sectioning of the AVF) Castier and coworkers mainly focused on the vascular response in the carotid artery while the majority of the human AVFs failed because of venous occlusive lesions. Furthermore, AVFs in hemodialysis patients are usually constructed by anatomizing the end of a vein to the side of an artery. The exact configuration of the AVF is a crucial characteristic of such model since it determines the hemodynamic profile within the fistula [8]. The latter is an important contributor to endothelial dysfunction and subsequent development of $\mathrm{IH}$ $[9,10]$.

Therefore, we recently developed a novel murine model with an identical anatomical configuration as is utilized in humans [11]. In this model, AVFs were created in C57BL/6 mice by anastomosing the end of a branch of the external jugular vein to the side of the common carotid artery with interrupted sutures. The AVFs were harvested at days 7, 14, and 28 after surgery. Near-infrared fluorescent fluorophores were administered to assess the patency of the fistula in vivo. Patency rates were $88 \%, 90 \%$ and $50 \%$ at days 7,14 , and 28 , respectively. Histological analysis of the venous outflow tract revealed, inflammatory cells infiltration, fragmentation of the internal elastic lamina (IEL) and progressive IH that mainly consisted of VSMCs and collagen. In addition, a 77\% increase in size of the vein (as determined by the circumference of the IEL) was observed in the first 14 days after surgery. The latter illustrates the important role of venous outward remodeling after AVF surgery. Indeed, the luminal caliber is the net resultant of initial vessel diameter, outward remodeling and thickening of the vessel wall due to IH and thrombosis [12]. In these murine studies, the complex microsurgical procedure remains a challenge that requires experienced surgeons. Therefore, other researchers developed AVF models in rats that are approximately 3 times larger in size and 10 times larger in weight.

\section{RAT MODELS}

The aorto-caval fistula model in the rat was originally developed to study the pathogenesis of cardiac hypertrophy and congestive heart failure cardiovascular effect of highoutput heart failure heart failure and cardiac hypertrophy [13]. In later studies published in the last decade, this model was used to assess the pathology that occurs in the AVF itself $[14,15]$. Studies from Taiwan showed marked elastinolysis of the IEL, which occurs already at 2 weeks after surgery, especially in the venous segment that is exposed to prominent hemodynamic changes [14]. In studies by Nath et al., aorto-caval fistulas were evaluated up to 16 weeks after surgery [15]. These studies revealed that IH is accompanied by an inflammatory response, as shown by upregulated inflammatory gene expression. No data on AVF patency were reported but it appears that the intimal thickening in the venous outflow tract did not result in failure of the AVFs. A limitation of the model is the side-toside configuration of the AVF that results in bidirectional outflow in the inferior vena cava and a different hemodynamic profile when compared to human AVFs in which the distal part of the vein is usually ligated. Furthermore, it's important to notice that the compensatory high cardiac output that occurs after creation of aorto-caval fistulas may lead to symptomatic congestive heart failure and mortality, especially in long-term follow up studies $[16,17]$. Finally, the creation of aorto-caval fistulas by puncturing the vena cava through the lateral aortic wall with a 22 -gauge needle could also result in a significant percentage of technical failure and acute mortality. In an effort to reduce this rate of technical failure, an adapted rat model of aortocaval fistula was recently described in which the aorta is connected to the inferior caval vein using the renal vein as vascular vascular graft [18]. The main limitation of this model is the deviant anatomical configuration of the AVF when compared to humans.

Most studies in rats were performed using the femoral artery and ipsilateral femoral vein to create AVF with a sideto-side [19] or end-to side configuration AVFs [20, 21]. In addition, Croatt, et al. described a model in which the end of the artery was anastomosed to the side of the vein [22]. While most studies $[19,20,22]$ evaluated the histology of the venous outflow tract at 4 weeks after surgery, Langer and coworkers [21] sacrificed the rats after 12 weeks of follow up. Again, upregulation of inflammatory genes and matrix metalloproteinases as well as progressive IH were observed in the venous outflow tract. Interestingly, the intimal hyperplastic lesions did not result in significant luminal loss at 12 weeks after surgery since it coincides with a 2 -fold increase in the venous diameter 8 [21].

Finally, AVFs have been constructed using the ventral artery and vein in the tail of rats [23]. In this small study that included 5 rats, AVFs were analyzed histologically at 28 days after surgery. The composition of $\mathrm{IH}$ in the draining vein was comparable with the lesions in AVFs at the abovementioned locations in the rat. Although technically challenging, the superficial location of the AVF in this model may have advantages over the other configurations since it allows the investigating of local subcutaneous or intravascular therapies. 
Overall, the development of hemodynamically significant stenotic lesions in AVFs is much slower in rats when compared to mice. Furthermore, the limited availability of knockout rats favors the use of mice for pathophysiological studies aimed to elaborate the role of specific genes and proteins involved in AVF failure.

\section{SHEEP AND GOAT MODELS}

Various experts in the field of vascular access-related complications have postulated that hemodynamic factors such as turbulent flow and the accompanying disturbance in shear stress levels, might contribute to the aggressive intimal hyperplastic response in the venous outflow tract of AVFs [8, 9, 24-26]. As defined by Poiseuille's formula, the luminal diameter is the most important determinant of shear stress. Therefore, larger animals with larger vessels seem more suitable to mimic the hemodynamic profile in human arteriovenous access conduits.

Kohler et al., developed a sheep model of AVG failure in which expanded polytetrafluoroethylene (ePTFE) grafts were implanted between the carotid artery and the contralateral external jugular vein [27]. The sheep weighted between 29 and $51 \mathrm{~kg}$ at time of surgery. AVG were harvested at 4,8 and 12 weeks after surgery. To prevent acute graft thrombosis, oral aspirin $(81 \mathrm{mg} /$ day $)$ was administered 1 day before surgery and once per day throughout the study. Despite aspirin therapy, 18\% (4/22) of grafts thrombosed in the first week after surgery. Histological analysis of the remained patent grafts revealed that the venous anastomoses developed a thick neointima within the PTFE graft that consisted of VSMCs, matrix proteins and thrombus. At 12 weeks of follow up, only $25 \%$ of grafts remained patent. In view of the formation of truly stenotic lesions leading to occlusion of the AVG, this model offers the potential to assess new therapeutic and preventive strategies since patency rate is the most relevant end point in such preclinical study. An important difference with human AVG is the large venous baseline diameter $(8.6 \mathrm{~mm})$ and the low initial graft flow $(460 \mathrm{ml} / \mathrm{min})$ in this sheep model. Another minor issue is the S-shaped curve from the artery to the vein that differs from the loop configuration that is commonly utilized in human.

Recently, Tilman et al., used this model to evaluate the efficacy of tissue engineered blood vessels as hemodialysis access graft [28]. They added clopidogrel to the antiplatelet therapy and implanted ex vivo engineered blood vessels that were monitored up to 6 months after surgery. Early failure rate van $27 \%$ whereas the mean primary patency of the graft that were patent at 1 month after surgery was 4.4 months. These data illustrate the suitability of this model for studies with novel grafts or tissue engineered blood vessels with a substantial duration of follow-up.

Lemson et al., developed a model arteriovenous access failure in goats. They created AVFs between the carotid artery and the jugular vein in 13 goats weighting about $60 \mathrm{~kg}$ and explanted them 10 to 195 days after surgery [29]. No antiplatelet therapy was administered. Juxta-anastomotic lesions developed with comparable composition as in humans. The progression of lesion formation appears relatively slow since the average intima/media ratio in the vein was $<1$ and none of the AVF was occluded at time of harvest. The latter limits the use of this model for interventional studies since large groups of animals are needed with low term follow-up in order to demonstrate a statistically significant reduction of IH or increase in AVF patency.

\section{DOG MODEL}

In dogs, intimal hyperplasia in ePTFE AVG has been investigated extensively [30-33]. Prosthetic vascular grafts were implanted between the femoral artery and the femoral vein of mongrel dogs weighing $20-30 \mathrm{~kg}$. No antiplatelet therapy was used. Again, IH developed mainly at the venous anastomosis although follow up to 12 weeks was insufficient to observe stenotic lesions resulting in graft failure. In subsequent intervention studies using tissue engineered grafts, progressive lesions were demonstrated resulting in primary patency rates of ePTFE AV-grafts of $57 \%$ at 6 and 12 months [34].

This model offers the opportunity to study the pathophysiology of AVG failure although the size of the vessels is smaller when compared to humans and implantation in the groin carries the risk of compression of the graft when the animal is in a supine position. Indeed, grafts placed over a flexion crease are known to exhibit reduced patency. For instance, 48 ePTFE conduits implanted in dogs for 3 months, kinking was noted in $50 \%$ of femoral grafts when compared to $17 \%$ of carotid grafts [35].

To the best of my knowledge, no AVF models have been described in dogs except a series of acute experiments investigating the effect of anastomotic size on fistula flow [36].

\section{PRIMATE MODELS}

Non-human primates resemble human anatomy and physiology more closely than other species, but their use is limited for many by ethical considerations, special housing and high costs. Various studies have utilized an arterial aortoiliac bypass graft model to study the effect of flow and VSMCs proliferation in ePTFE grafts $[37,38]$. In recent studies, AV-graft models were developed in which tissue engineered vascular grafts (TEVG) were placed between the axillary artery and the distal brachial vein, which provided a superficial site amenable for simulating hemodialysis access $[39,40]$. TEVG with an internal diameter of $6 \mathrm{~mm}$ were implanted in adult male baboons weighing $20-30 \mathrm{~kg}$ that were treated with aspirin $10 \mathrm{mg} / \mathrm{kg}$ for the duration of follow up (6 months). In the control group (2 baboons) ePTFE grafts were implanted with a follow-up of 1 and 6 months. Duplex ultrasound was used to monitor the diameter of TEVG during the study. Histological analysis demonstrated that TEVGs had substantially less intimal hyperplasia at the venous anastomosis than ePTFE grafts. Remarkably, the ePTFE AV-grafts were still patent at time of harvest, which illustrates that the formation of IH is not as aggressive as in other large animal models such as pigs. 


\section{PIG MODELS}

Pigs are frequently used in cardiovascular studies because of their analogous vascular anatomy, size and physiology [41-43]. The rapid formation of stenotic lesions in the porcine vasculature upon injury (3-6 times faster as in humans) [44], provides the opportunity to investigate the pathophysiology as well as the efficacy of novel therapeutic strategies aimed to improve arteriovenous access durability. In the last 2 decades, both AVF models and AVG models have been developed in pigs.

The group of dr. Roy-Chaudhury in Cincinnati developed a porcine model in which AVFs were created bilaterally between the femoral artery $(4 \mathrm{~mm})$ and femoral vein $(6 \mathrm{~mm})$ in Yorkshire Cross pigs weighing $50 \mathrm{~kg}$ [45]. All pigs were administered aspirin $325 \mathrm{mg}$ daily from the day before surgery to the time of sacrifice at 2 days, 7 days, 28 days or 42 days after surgery, up to 42 days after surgery. Significant luminal stenosis due to $\mathrm{IH}$ was present at 28 days, mainly in the proximal vein and juxta-anastomotic segment. Additional studies from the same laboratory provided data on AVF vessel size and hemodynamic parameters in this model [46]. Blood velocity measurements were obtained by ultrasound and quantification of both the configuration and the internal diameter of the fistulae was determined by CT scans. AVF flow increased from approximately $1000 \mathrm{ml} / \mathrm{min}$ directly after surgery to $2760-3890 \mathrm{ml} / \mathrm{min}$ at 4 weeks, depending on the configuration of the anastomosis (curved or straight, respectively). Concurrently, the luminal diameter of the proximal vein increased from $4 \mathrm{~mm}$ up to $6.2-10.6 \mathrm{~mm}$, again depending of the AVF configuration (curved or straight). These data suggest that there might be a possible link between anatomic configuration, venous dilation and AVF flow.

In view of the high flow values and larger diameters, this model offers the opportunity to investigate vascular adaptation in high output fistulas, comparable to upper arm fistulas in humans.

In the last decade, various porcine AVG models have been described [47-49]. Johnson and coworkers described an AVG model in which $4 \mathrm{~mm}$ ePTFE grafts were implanted unilaterally between the iliac artery and iliac vein of mixedbreed pigs weighing 25 to $46 \mathrm{~kg}$ [47]. At the contralateral side, an AVF was created. Each pig was given aspirin $325 \mathrm{mg}$ by mouth 24 hours before the initial procedure and $650 \mathrm{mg}$ by mouth the morning of the procedure. For the duration of the study (up to 64 days) pigs were treated with high dose aspirin (325 mg four times daily) to prevent acute graft thrombosis. The initial graft flow in this model was $472 \mathrm{ml} / \mathrm{min}$. AVG patency at $42-64$ days was $80 \%$. Histological analysis revealed intimal hyperplastic lesions that resulted in $70-80 \%$ stenosis, mainly in the area of the venous anastomosis. Kelly and coworkers [48] slightly adapted this model by implanting $4 \mathrm{~mm}$ ePTFE grafts bilaterally between the femoral artery and femoral vein. Aspirin dose was reduced to $325 \mathrm{mg}$ daily. Pigs were sacrificed at 2, 4, 7, 14 and 28 days post-surgery. All AVG were patent at time of harvest. Again, aggressive venous neointimal hyperplasia was observed near the venous anastomosis, resulting in venous stenosis ranging from $0 \%$ at day 2 to $52.5 \%$ at day 28 .
At our laboratory, we developed a porcine model in which $5 \mathrm{~mm}$ ePTFE graft were implanted bilaterally between the carotid artery and the jugular vein in pigs with a mean weight of $57 \mathrm{~kg}$ [49]. The latter approach might reduce the risk of graft compression as compared to implantation in the groin [35]. Of note, no signs of cerebral ischemia were detected during EEG registration after implantation of the bilateral AV-grafts.

Starting 6 days preoperatively, the pigs received aspirin $80 \mathrm{mg} /$ day and clopidogrel $225 \mathrm{mg}$ was added 1 day preoperatively and continued at a dose of $75 \mathrm{mg}$ /day until termination up to 8 weeks after surgery. We choose this regimen since we experienced an unacceptable high rate of acute graft thrombosis in earlier studies when using low dose aspirin monotherapy. Mean initial graft flow was $829 \mathrm{ml} / \mathrm{min}$ that is comparable to the human situation. At a histological level, truly stenotic lesions were encountered in this model within a relatively short period of 4 weeks. At 8 weeks, patency rates declined below $50 \%$ due to thrombus formation superimposed on progressive $\mathrm{IH}$. The composition of intimal hyperplastic lesions resembled lesions human AVgrafts described by different groups [50-52]. Indeed, lesions were mainly localized near the venous anastomosis and are characterized by proliferating VSMCs, microvessels, macrophages and extracellular matrix components.

In these porcine models, AVG were created bilaterally. This approach provides a potent model for investigating therapeutic approaches, since one graft can be experimentally manipulated while the other graft is used as a control. This allows each animal to serve as its own internal control, avoiding the inter-animal variability associated with unilateral AVG models [53].

In Table 1, the above-mentioned animal models are summarized.

\section{UREMIC VERSUS NON-UREMIC ANIMALS}

The validity of using animal studies for vascular intervention studies as models for the human situation has been a matter of debate. This skepticism mainly relates to the use of relatively healthy animals that show a different response to (vascular) injury. The animal model described thus far, lacks risk factors such as theuremic milieu that may have a clear impact on vascular changes and the formation of IH in AV conduits.

To investigate the mechanisms of vascular pathology in chronic kidney disease (CKD), nephrectomy remnant models in rats [54], mice [55], rabbits [56], dogs [57], baboons [58], and pigs [59, 60] have been used for many years. More recently, various researchers successfully integrated these CKD models in their animal model of vascular access failure.

Kuboko et al., [61] constructed AVFs using the carotid artery and the jugular vein in an end-to side fashion in CKD mice. To induce CKD, they used a two-step renal ablation procedure. First, cortical electrocautery was applied to the right kidney through a $2-\mathrm{cm}$ flank incision whereupon total left nephrectomy was performed 2 weeks later. Another 6 weeks later, AVFs were created and mice were sacrificed at 3 weeks after AVF surgery. 
Table 1. Overview of animal models (species, location, AVF/AVG, diameters, flow values, patency, advantages/limitations). Abbreviations: $A V F=$ arteriovenous fistula. AVG $=$ arteriovenous graft. $A=$ artery. $V=$ vein. NIRF $=$ near-infrared fluorescence. TEVG = tissue engineered vascular graft. IVUS = intravascular ultrasonography.

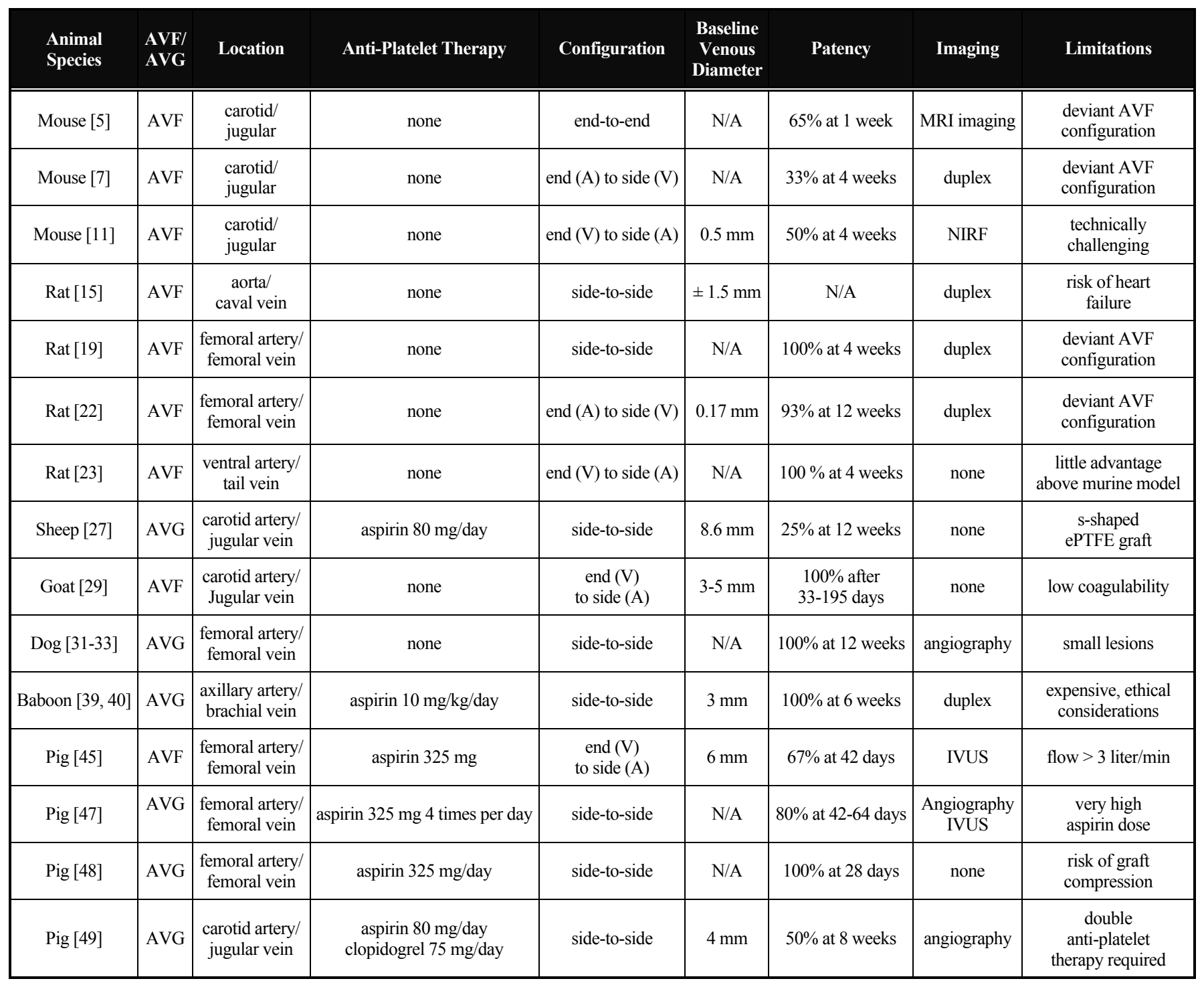

Whereas, thrombus volume in the venous outflow tract of the AVF did not differ between CKD and control mice, IH at the site of the AV anastomosis increased 2-fold in CKD animals. This study demonstrates that CKD has a profound effect on the development of $\mathrm{IH}$ at the anastomosis of murine AVF. Therefore, this combined model is a valuable addition to the AVF animal model arsenal although it should be noted that, as in most murine AVF studies, the end of the artery was anastomosed to side of the vein instead of the other way around.

Langer et al., developed a model in rats [62] in which AVFs were created between the femoral artery and femoral vein in a chemical nephrectomy model to induce CKD. AVFs were created in an end-to-side configuration similar as in humans. Rats were sacrificed at 84 days after AVF surgery. Imaging studies using MRI revealed that venous dilation was impaired in the CKD rats in the first 3 weeks after surgery. In addition, a substantial increase in IH and calcification was observed in the venous outflow tract of
AVFs of CKD rats. These observations suggest that CKD itself could contribute to maturation failure of AVF.

The group of dr. Misra from the Mayo Clinic developed an ePTFE AVG graft model in CKD pigs in which CKD was induced by subtotal embolization of the renal arterial vasculature $[63,64]$. AVG were created bilaterally between the carotid artery and the ipsilateral jugular vein. There were no complications as a result of the embolization procedure other than the expected induction of renal insufficiency. Pigs were sacrificed at 14 days after AVG surgery. Again, IH was observed in the venous outflow tract. However, no direct comparison was made with non-CKD pigs. Therefore, the potential contribution of $\mathrm{CKD}$ in $\mathrm{AVG}$ failure in pigs remains to be elucidated.

Although these combined models are technically challenging and might result in a larger percentage of technical failure, the incorporation of chronic renal failure in animal models for vascular access failure, unarguably 
improves the validity of these models for human hemodialysis access failure.

\section{CHRONIC HEMODIALYSIS}

Another limitation of most animal models is the absence of repetitive insertion of needles into the grafts and the hemodialysis itself that obviously might contribute to vascular access failure as well. Intermittent hemodialysis has emerged as a feasible treatment option for small animals such as cats and dogs that suffer from acute renal failure [65]. However, chronic intermittent hemodialysis in animal with experimentally induced chronic renal failure is a far more complicated story. Bower et al., [66] described an model of chronic hemodialysis in anephric goats more than 30 years ago. However, the poor health of the animals, the need for repetitive anesthesia during the hemodialysis sessions, the unacceptable high burden of discomfort for the animals as well as the high costs limit the feasibility of such model.

\section{COAGULATION AND ANTI-PLATELET THERAPY}

In view of the important role for the coagulation system in the pathophysiology of AV access stenosis and thrombosis, comparative analysis of this system of various species is essential when determining the validity of animal models of AV access failure. These comparative studies have shown that the clotting and fibrinolytic systems of the calf and non-human primates are more similar to humans than those of dogs or pigs [4]. In example, analytical studies on the coagulation system of pigs revealed a tendency to hypercoagulability in these animals when compared to humans [67]. Furthermore, platelet attachment to immobilized fibrinogen differs substantially between species and appeared to be greatest in humans, lowest for sheep, and in between for pigs [68]. Finally, hematocrit and platelet count, both important factors in rheology/shear stress and coagulation, vary significantly between species [4]. It's important to keep these differences in mind when selecting a suitable animal species and the required anti-platelet therapy that is required to prevent acute thrombosis of the AV access conduit, especially for studies in which new strategies to prevent vascular access occlusion or thrombosis are evaluated. In our porcine model of AVG failure [49] profound anti-platelet therapy withaspirin and clopidogrel is mandatory to prevent early thrombotic graft failure. However, this anti-platelet regime is not applicable in humans since a disproportionate increase in bleeding complications has been observed using this regime in patients on chronic hemodialysis [69]. Therefore, one should be cautious in extrapolating the results from studies to uremic patients on chronic hemodialysis.

\section{ENDOTHELIALISATION OF PROSTHETIC GRAFTS}

In humans, prosthetic vascular grafts remain largely without an endothelium, even after decades of implantation. Transanastomotic endothelial ingrowth does not exceed more than 1-2 $\mathrm{cm}$ [70]. In this respect, it's important to be aware that the extent and speed of this endothelial ingrowth strongly depend on the type and length of the prosthetic graft as well as the age and species of the animals that are used [71]. In example, the same ingrowth distance for which humans need 56 weeks [70] is reached after 4 weeks in young baboons [72] and 3.5 weeks in dogs [73]. These differences should be taken into account when interpreting the effects of interventions such as cell seeding of prosthetic grafts.

\section{CONCLUSION}

Animal models can provide novel mechanistic insights into arteriovenous access failure and are useful for preclinical assessment of novel therapeutic interventions. However, the translation rate from preclinical studies to the bedside remains low, likely due to differences in physiology and molecular pathways. Only about a third of highly cited animal research translated at the level of human randomized trials [74]. A clinical understanding of the mechanisms responsible for AV access failure combined with extensive knowledge of the (patho)physiology in the animal to be used, may increase the predictive value of the animal models. While large animals such as pigs are suitable for intervention studies, murine models have the greatest potential to gain more insight in the molecular mechanisms underlying AV access failure. The biggest challenge remains to translate experimental findings from these animal studies into clinical benefits for hemodialysis patients that suffer from an enormous burden of vascular access related complications.

\section{CONFLICT OF INTEREST}

The author confirms that this article content has no conflict of interest.

\section{ACKNOWLEDGEMENTS}

Declared none.

\section{REFERENCES}

[1] Roy-Chaudhury P, Sukhatme VP, Cheung AK. Hemodialysis vascular access dysfunction: a cellular and molecular viewpoint. J Am Soc Nephrol 2006; 17(4): 1112-27.

[2] Rotmans JI, Pasterkamp G, Verhagen HJ, Pattynama PM, Blankestijn PJ, Stroes ES. Hemodialysis access graft failure: time to revisit an unmet clinical need? J Nephrol 2005; 18(1): 9-20.

[3] Lee T, Roy-Chaudhury P. Advances and new frontiers in the pathophysiology of venous neointimal hyperplasia and dialysis access stenosis. Adv Chronic Kidney Dis 2009; 16(5): 329-38.

[4] Byrom MJ, Bannon PG, White GH, Ng MK. Animal models for the assessment of novel vascular conduits. J Vasc Surg 2010; 52(1): 176-95.

[5] Kwei S, Stavrakis G, Takahas M, et al. Early adaptive responses of the vascular wall during venous arterialization in mice. Am J Pathol 2004; 164(1): 81-9.

[6] Yang B, Shergill U, Fu AA, Knudsen B, Misra S. The mouse arteriovenous fistula model. J Vasc Interv Radiol 2009; 20(7): 94650

[7] Castier $\mathrm{Y}$, Lehoux $\mathrm{S}, \mathrm{Hu} \mathrm{Y}$, Foteinos $\mathrm{G}$, Tedgui A, Xu Q. Characterization of neointima lesions associated with arteriovenous fistulas in a mouse model. Kidney Int 2006; 70(2): 315-20.

[8] Krishnamoorthy MK, Banerjee RK, Wang Y, et al. Hemodynamic wall shear stress profiles influence the magnitude and pattern of stenosis in a pig AV fistula. Kidney Int 2008; 74(11): 1410-9.

[9] Ene-Iordache B, Cattaneo L, Dubini G, Remuzzi A. Effect of anastomosis angle on the localization of disturbed flow in 'side-toend' fistulae for haemodialysis access. Nephrol Dial Transplant 2013; 28(4): 997-1005. 
[10] Sivanesan S, How TV, Bakran A. Sites of stenosis in AV fistulae for haemodialysis access. Nephrol Dial Transplant 1999; 14(1): 118-20.

[11] Wong CY, de Vries MR, Wang Y, et al. Vascular remodeling and intimal hyperplasia in a novel murine model of arteriovenous fistula failure. J Vasc Surg 2014; 59(1): 192-201.

[12] Rothuizen TC, Wong C, Quax PH, van Zonneveld AJ, Rabelink TJ, Rotmans JI. Arteriovenous access failure: more than just intimal hyperplasia? Nephrol Dial Transplant 2013; 28(5): 1085-92.

[13] Winaver J, Hoffman A, Burnett JC Jr, Haramati A. Hormonal determinants of sodium excretion in rats with experimental highoutput heart failure. Am J Physiol 1988; 254(5 Pt 2): R776-84.

[14] Chang CJ, Chen CC, Hsu LA, et al. Degradation of the internal elastic laminae in vein grafts of rats with aortocaval fistulae: potential impact on graft vasculopathy. Am J Pathol 2009; 174(5): 1837-46.

[15] Nath KA, Kanakiriya SK, Grande JP, Croatt AJ, Katusic ZS. Increased venous proinflammatory gene expression and intimal hyperplasia in an aorto-caval fistula model in the rat. Am J Pathol 2003; 162(6): 2079-90.

[16] Brower GL, Janicki JS. Contribution of ventricular remodeling to pathogenesis of heart failure in rats. Am J Physiol Heart Circ Physiol 2001; 280(2): H674-83.

[17] Melenovsky V, Skaroupkova P, Benes J, Torresova V, Kopkan L, Cervenka L. The course of heart failure development and mortality in rats with volume overload due to aorto-caval fistula. Kidney Blood Press Res 2012; 35(3): 167-73.

[18] Manning E, Skartsis N, Orta AM, et al. A new arteriovenous fistula model to study the development of neointimal hyperplasia. J Vasc Res 2012; 49(2): 123-31.

[19] Misra S, Fu AA, Anderson JL, et al. The rat femoral arteriovenous fistula model: increased expression of matrix metalloproteinase-2 and -9 at the venous stenosis. J Vasc Interv Radiol 2008; 19(4): 587-94.

[20] Chan CY, Chen YS, Ma MC, Chen CF. Remodeling of experimental arteriovenous fistula with increased matrix metalloproteinase expression in rats. J Vasc Surg 2007; 45(4): 80411.

[21] Langer S, Heiss C, Paulus N, et al. Functional and structural response of arterialized femoral veins in a rodent AV fistula model. Nephrol Dial Transplant 2009; 24(7): 2201-6.

[22] Croatt AJ, Grande JP, Hernandez MC, Ackerman AW, Katusic ZS, Nath KA. Characterization of a model of an arteriovenous fistula in the rat: the effect of L-NAME. Am J Pathol 2010; 176(5): 2530-41.

[23] Lin T, Horsfield C, Robson MG. Arteriovenous fistula in the rat tail: a new model of hemodialysis access dysfunction. Kidney Int 2008; 74(4): 528-31.

[24] Asif A, Roy-Chaudhury P, Beathard GA. Early arteriovenous fistula failure: a logical proposal for when and how to intervene. Clin J Am Soc Nephrol 2006; 1(2): 332-9.

[25] Ene-Iordache B, Remuzzi A. Disturbed flow in radial-cephalic arteriovenous fistulae for haemodialysis: low and oscillating shear stress locates the sites of stenosis. Nephrol Dial Transplant 2012; 27(1): 358-68.

[26] Roy-Chaudhury P, Spergel LM, Besarab A, Asif A, Ravani P. Biology of arteriovenous fistula failure. J Nephrol 2007; 20(2): 150-63.

[27] Kohler TR, Kirkman TR. Dialysis access failure: A sheep model of rapid stenosis. J Vasc Surg 1999; 30(4): 744-51.

[28] Tillman BW, Yazdani SK, Neff LP, et al. Bioengineered vascular access maintains structural integrity in response to arteriovenous flow and repeated needle puncture. J Vasc Surg 2012; 56(3): 78393.

[29] Lemson MS, Daemen MJ, Kitslaar PJ, Tordoir JH. A new animal model to study intimal hyperplasia in arteriovenous fistulas. J Surg Res 1999; 85(1): 51-8.

[30] Fillinger MF, Kerns DB, Bruch D, Reinitz ER, Schwartz RA. Does the end-to-end venous anastomosis offer a functional advantage over the end-to-side venous anastomosis in high-output arteriovenous grafts? J Vasc Surg 1990; 12(6): 676-88; discussion 688-90.

[31] Fillinger MF, Reinitz ER, Schwartz RA, Resetarits DE, Paskanik AM, Bredenberg CE. Beneficial effects of banding on venous intimal-medial hyperplasia in arteriovenous loop grafts. Am J Surg $1989 ; 158(2): 87-94$.
[32] Fillinger MF, Reinitz ER, Schwartz RA, et al. Graft geometry and venous intimal-medial hyperplasia in arteriovenous loop grafts. J Vasc Surg 1990; 11(4): 556-66.

[33] Trerotola SO, Carmody TJ, Timmerman RD, et al. Brachytherapy for the prevention of stenosis in a canine hemodialysis graft model: preliminary observations. Radiology 1999; 212(3): 748-54.

[34] Matsuura JH, Black KS, Levitt AB, et al. Cellular remodeling of depopulated bovine ureter used as an arteriovenous graft in the canine model. J Am Coll Surg 2004; 198(5): 778-83.

[35] Wilson GJ, MacGregor DC, Klement P, Weber BA, Binnington AG, Pinchuk L. A compliant Corethane/Dacron composite vascular prosthesis. Comparison with 4-mm ePTFE grafts in a canine model. ASAIO J 1993; 39(3): M526-31.

[36] Ramacciotti E, Galego SJ, Gomes M, Goldenberg S, De Oliveira Gomes P, Pinto Ortiz J. Fistula size and hemodynamics: an experimental model in canine femoral arteriovenous fistulas. J Vasc Access 2007; 8(1): 33-43.

[37] Hanson SR, Powell JS, Dodson T, et al. Effects of angiotensin converting enzyme inhibition with cilazapril on intimal hyperplasia in injured arteries and vascular grafts in the baboon. Hypertension 1991; 18(Suppl 4): II70-6.

[38] Kohler TR, Kirkman TR, Kraiss LW, Zierler BK, Clowes AW. Increased blood flow inhibits neointimal hyperplasia in endothelialized vascular grafts. Circ Res 1991; 69(6): 1557-65.

[39] Dahl SL, Kypson AP, Lawson JH, et al. Readily available tissueengineered vascular grafts. Sci Transl Med 2011;3(68): 68ra9.

[40] Prichard HL, Manson RJ, DiBernardo L, Niklason LE, Lawson JH, Dahl SL. An early study on the mechanisms that allow tissueengineered vascular grafts to resist intimal hyperplasia. J Cardiovasc Transl Res 2011; 4(5): 674-82.

[41] Ferrell M, Fuster V, Gold HK, Chesebro JH. A dilemma for the 1990s. Choosing appropriate experimental animal model for the prevention of restenosis. Circulation 1992; 85(4): 1630-1.

[42] Johnson GJ, Griggs TR, Badimon L. The utility of animal models in the preclinical study of interventions to prevent human coronary artery restenosis: analysis and recommendations. On behalf of the Subcommittee on Animal, Cellular and Molecular Models of Thrombosis and Haemostasis of the Scientific and Standardization Committee of the International Society on Thrombosis and Haemostasis. Thromb Haemost 1999; 81(5): 835-43.

[43] Narayanaswamy M, Wright KC, Kandarpa K. Animal models for atherosclerosis, restenosis, and endovascular graft research. J Vasc Interv Radiol 2000; 11(1): 5-17.

[44] Fischell TA, Virmani R. Intracoronary brachytherapy in the porcine model: a different animal. Circulation 2001; 104(20): 2388-90.

[45] Wang Y, Krishnamoorthy M, Banerjee R, et al. Venous stenosis in a pig arteriovenous fistula model--anatomy, mechanisms and cellular phenotypes. Nephrol Dial Transplant 2008; 23(2): 525-33.

[46] Krishnamoorthy MK, Banerjee RK, Wang Y, Choe AK, Rigger D, Roy-Chaudhury P. Anatomic configuration affects the flow rate and diameter of porcine arteriovenous fistulae. Kidney Int 2012; 81(8): 745-50.

[47] Johnson MS, McLennan G, Lalka SG, Whitfield RM, Dreesen RG. The porcine hemodialysis access model. J Vasc Interv Radiol 2001; 12(8): 969-77.

[48] Kelly BS, Heffelfinger SC, Whiting JF, et al. Aggressive venous neointimal hyperplasia in a pig model of arteriovenous graft stenosis. Kidney Int 2002; 62(6): 2272-80.

[49] Rotmans JI, Velema E, Verhagen HJ, et al. Rapid, arteriovenous graft failure due to intimal hyperplasia: a porcine, bilateral, carotid arteriovenous graft model. J Surg Res 2003; 113(1): 161-71.

[50] Rekhter M, Nicholls S, Ferguson M, Gordon D. Cell proliferation in human arteriovenous fistulas used for hemodialysis. Arterioscler Thromb 1993; 13(4): 609-17.

[51] Roy-Chaudhury P, Kelly BS, Miller MA, et al. Venous neointimal hyperplasia in polytetrafluoroethylene dialysis grafts. Kidney Int 2001; 59(6): 2325-34.

[52] Swedberg SH, Brown BG, Sigley R, Wight TN, Gordon D, Nicholls SC. Intimal fibromuscular hyperplasia at the venous anastomosis of PTFE grafts in hemodialysis patients. Clinical, immunocytochemical, light and electron microscopic assessment. Circulation 1989; 80(6): 1726-36.

[53] Jones DN, Rutherford RB, Ikezawa T, Nishikimi N, Ishibashi H, Whitehill TA. Factors affecting the patency of small-caliber prostheses: observations in a suitable canine model. J Vasc Surg 1991; 14(4): 441-8; discussion 448-51. 
[54] Heifets M, Morrissey JJ, Purkerson ML, Morrison AR, Klahr S. Effect of dietary lipids on renal function in rats with subtotal nephrectomy. Kidney Int 1987; 32(3): 335-41.

[55] Ma LJ, Fogo AB. Model of robust induction of glomerulosclerosis in mice: importance of genetic background. Kidney Int 2003; 64(1): 350-5.

[56] Fine LG, Trizna W, Bourgoignie JJ, Bricker NS. Functional profile of the isolated uremic nephron. Role of compensatory hypertrophy in the control of fluid reabsorption by the proximal straight tubule. J Clinical Invest 1978; 61(6): 1508-18.

[57] Bourgoignie JJ, Gavellas G, Martinez E, Pardo V. Glomerular function and morphology after renal mass reduction in dogs. J Lab Clin Med 1987; 109(4): 380-8.

[58] Bourgoignie JJ, Gavellas G, Sabnis SG, Antonovych TT. Effect of protein diets on the renal function of baboons (Papio hamadryas) with remnant kidneys: a 5-year follow-up. Am J Kidney Dis 1994; 23(2): 199-204.

[59] McKenna PH, Khoury AE, McLorie GA, Reid G, Churchill BM. A surgical model for normotensive chronic renal failure in the growing piglet. J Urol 1992; $148(2$ Pt 2): 756-9.

[60] Misra S, Gordon JD, Fu AA, et al. The porcine remnant kidney model of chronic renal insufficiency. J Surg Res 2006; 135(2): 370-

[61] Kokubo T, Ishikawa N, Uchida H, et al. CKD accelerates development of neointimal hyperplasia in arteriovenous fistulas. J Am Soc Nephrol 2009; 20(6): 1236-45.

[62] Langer S, Paulus N, Koeppel TA, et al. Cardiovascular remodeling during arteriovenous fistula maturation in a rodent uremia model. J Vasc Access 2011; 12(3): 215-23.

[63] Hughes D, Fu AA, Puggioni A, et al. Adventitial transplantation of blood outgrowth endothelial cells in porcine haemodialysis grafts alleviates hypoxia and decreases neointimal proliferation through a matrix metalloproteinase-9-mediated pathway--a pilot study. Nephrol Dial Transplant 2009; 24(1): 85-96.
[64] Misra S, Fu AA, Puggioni A, et al. Increased expression of hypoxia-inducible factor-1 alpha in venous stenosis of arteriovenous polytetrafluoroethylene grafts in a chronic renal insufficiency porcine model. J Vasc Interv Radiol 2008; 19(2 Pt 1): 260-5.

[65] Eatroff AE, Langston CE, Chalhoub S, Poeppel K, Mitelberg E. Long-term outcome of cats and dogs with acute kidney injury treated with intermittent hemodialysis: 135 cases (1997-2010). J Am Veter Medl Assoc 2012; 241(11): 1471-8

[66] Bower JD, Holbert RD, Pearson JE, Jones Q, Bengis R, Berndt WO. Chronic hemodialysis in the anephric goat. Nephron 1980; 25(1): 34-9.

[67] Kostering H, Mast WP, Kaethner T, Nebendahl K, Holtz WH Blood coagulation studies in domestic pigs (Hanover breed) and minipigs (Goettingen breed). Lab Anim 1983; 17(4): 346-9.

[68] Pelagalli A, Belisario MA, Tafuri S, et al. Adhesive properties of platelets from different animal species. J Comp Pathol 2003; 128(23): 127-31.

[69] Kaufman JS, O'Connor TZ, Zhang JH, et al. Randomized controlled trial of clopidogrel plus aspirin to prevent hemodialysis access graft thrombosis. J Am Soc Nephrol 2003; 14(9): 2313-21.

[70] Berger K, Sauvage LR, Rao AM, Wood SJ. Healing of arteria prostheses in man: its incompleteness. Ann Surg 1972; 175(1): 118-27.

[71] Zilla P, Bezuidenhout D, Human P. Prosthetic vascular grafts: wrong models, wrong questions and no healing. Biomaterials 2007; 28(34): 5009-27.

[72] Clowes AW, Gown AM, Hanson SR, Reidy MA. Mechanisms of arterial graft failure. 1. Role of cellular proliferation in early healing of PTFE prostheses. Am J Pathol 1985; 118(1): 43-54.

[73] Hanel KC, McCabe C, Abbott WM, Fallon J, Megerman J. Current PTFE grafts: a biomechanical, scanning electron, and light microscopic evaluation. Ann Surg 1982; 195(4): 456-63.

[74] Hackam DG, Redelmeier DA. Translation of research evidence from animals to humans. Am J Med Assoc 2006; 296(14): 1731-2. 